\title{
- High Prevalence and Increasing Incidence of Multiple Sclerosis in the Norwegian County of Buskerud -
}

\author{
Authors: Cecilia Smith Simonsen 1,2,3, Astrid Edland 1, Pål Berg-Hansen 2, Elisabeth Gulowsen Celius 2 \\ 1 Department of Neurology, Drammen Hospital, Vestre Viken HF, Norway \\ 2 Department of Neurology, Oslo University Hospital, Norway \\ 3 Institute of Clinical Medicine, University of Oslo, Norway
}

\section{Objectives}

The objective was to investigate the incidence of multiple sclerosis (MS) as well as estimate the prevalence as of $1^{\text {st }}$ January 2014 in the south-eastern Norwegian county of Buskerud.

Materials and Methods

All MS patients living in Buskerud county in Norway between 01.01.2003 and 01.01.2014 were identified. Point prevalence of MS was identified on 01.01.2014.

\section{Results}

We found a prevalence of 213.8 ( $95 \% \mathrm{Cl} 196.4$ to 231.1 ) per 100000 . The sex ratio was 2.2:1 with a female prevalence of 293.4 ( $95 \% \mathrm{Cl} 264.7$ to 322.2 ) per 100000 and a male prevalence of 134.7 (95\% $\mathrm{Cl} 115.3$ to 154.2 ) per 100 000. 82\% of our MS population had a confirmed relapsing remitting MS at disease onset while $16.8 \%$ had primary progressive MS. The mean annual incidence between 2003 and 2013 was 11.8 (95\% Cl 10.6 to 13.1) per 100000.

\section{Conclusion}

This study shows a high incidence of MS in Buskerud county in South-Eastern Norway and the incidence may still be on the rise. We found a relatively high prevalence of MS in our population, though this does correspond with the recently published national data. Further studies investigating both changes in incidence and possible factors causing the increasing incidence are warranted.

Key Words: Epidemiology, Incidence, Multiple Sclerosis, Norway, Prevalence 


\section{Introduction}

Multiple sclerosis (MS) is an inflammatory disease with secondary neurodegeneration that causes significant disability in young people over time (1). Norway has a high prevalence of MS and a long history of epidemiological studies. Swank (2) was the first to evaluate the MS population size back in 1952 and found an annual incidence rate of 2.7/100 000 between 1935 and 1948. In a review article published in 2012 a nationwide prevalence of 165/100 000 and an incidence of 5.6/100 000 was estimated based on older epidemiological studies performed in Norwegian counties (3). The first nationwide prevalence study published in 2014 reported a prevalence of 203/100 000 (4).

The MS population in Buskerud has not been studied previously. The population is well defined with easy access to neurological services for decades, which allows us to follow the population over time. The aim of this study was to determine the prevalence and incidence of MS in Buskerud.

\section{Material and Methods}

\section{Geographical Setting}

Buskerud had a population of 272228 as of 1st January 2014. Almost $8 \%$ of the population were of non-Western ethnicity with the majority of these living in or around Drammen, which is the largest city and administrative centre. The latitude is aproximately $60^{\circ} \mathrm{N}$ and the area is $14.927 \mathrm{~km}^{2}$. Buskerud extends from the $123 \mathrm{~km}$ coastline in the Oslofjord with the main city of Drammen in the south-east, to the Hardanger plateau in the west and the Halling mountains (1 930 meters above sea level) (5) in the north-west (Fig. 1).

\section{Patient Material}

Every Norwegian citizen has a unique personal identification number. All patients registered with a diagnosis of MS between 01.01.2003 and 01.01.2014 were identified by an electronic search in the hospital and private clinic databases using the ICD-10 code G35 (MS). Drammen Hospital and two private neurology institutions provide neurology services for the population in Buskerud. The search was performed once in February 2014. Patients who fulfilled the Poser criteria for definite or probable MS (6) before 2001 or the McDonald criteria for MS (7-9) after 2001 and were residing in Buskerud as of January 2014 were included. All patients' journals were scrutinised by the first author.

Time of onset was defined as year of onset of symptoms suggestive of MS. Patients were classified as either having relapsing-remitting (RR) MS or primary progressive (PP) MS (10), though 7 elderly patients could not be reliably classified retrospectively. If the patient had more than one onset symptom, the one with the strongest impact on daily living was recorded.

\section{Incidence and Prevalence}

A Poisson distribution was assumed and $95 \% \mathrm{Cl}$ was calculated for both prevalence and incidence. We calculated the crude point prevalence as of 01.01 .14 by dividing the total number of MS patients residing in Buskerud by the total population of Buskerud (272 228 according to numbers provided by statistics Norway 01.01.14- www.ssb.no) multiplied by 100 000. We also calculated incidence based on year of diagnosis in two 5-year-periods. All patients were diagnosed according to McDonald criteria (either 2001(9), 2005(8) or 2010(7)). The number of patients with the diagnosis was divided by the population as of 1st January the same year. 


\section{Statistical Analysis}

We used SPSS software version 21 for statistical analysis. For calculating confidence intervals we used OpenEpi (www.OpenEpi.com). Comparison of age at diagnosis between PP-MS and RR-MS, comparison between incidence in the two 5-year groups, comparison between the delays from onset to diagnosis in those diagnosed before and after 2005 and comparison of patients with sensory symptoms at onset before and after 2005, were performed with independent-sample 2 tailed $t$ tests. Age standardised incidence and prevalence, according to the European standard population (http://www.who.int/healthinfo/paper31.pdf), was calculated by direct method. The study was classified as an internal audit and was approved by the Data Protection Officer at Drammen Hospital.

\section{Results}

\section{Prevalence}

A total of 936 patients were identified of whom 633 were included and 303 patients were excluded, either due to residency outside of Buskerud or not fulfilling the diagnostic criteria. 52 patients were deceased, leaving 582 living patients with MS residing in Buskerud as of 01.01.14, yielding a prevalence of $213.8 / 100000$. This was slightly higher than the prevalence adjusted to the European average, which was 197.1/100 000. The year of diagnosis ranged from 1959 to $2013.13 .1 \%(n=76)$ were diagnosed before 1991, 23.7\% ( $n=138$ ) were diagnosed between 1991 and 2000, 44.3\% ( $n=258)$ were diagnosed between 2001 and 2010 and 18.4\% ( $n=107)$ were diagnosed between 2011 and 2013. Year of diagnosis was unknown in 3 patients. The sex ratio was 2.2:1 with a female prevalence of $293.4 / 100000$ and a male prevalence of $134.7 / 100000$. At time of diagnosis, $82 \%$ of patients had relapsing remitting disease, while $16.8 \%$ had primary progressive disease. On prevalence day, the mean age of the patients was 52.7 years, ranging from 16.9 to 84.5 years. The median age was 53.4 years. The mean age of patients with RR-MS or secondary progressive disease (SP-MS) was 51.5 years (median 51.7), while the mean age of patients with PP-MS was 58.0 years (median 57.6). The mean age of those patients who still had a relapsing disease was 45.9 years (median 47) (Fig. 2).

On prevalence day $53.6 \%$ of the patient population were considered to have a relapsing-remitting disease phenotype while $28.4 \%$ had a secondary progressive disease.

\section{Incidence}

The mean yearly incidence of MS between 2003 and 2013 was 11.8/100 000. After adjusting the data to the European standard population, the incidence fell slightly to $11.5 / 100000$. In the 5 year period between 2003 and 2007 the incidence in Buskerud was 10.2/100 000 and between 2008 and 2012 it was 13.1/100 $000(p<0.01)$. The incidence was twice as high in women as in men (Fig. 3). Age specific incidence rates based on year of diagnosis are shown in table 3.

The mean age of onset in relapsing-remitting MS was 33.6 years (median 33) and the mean age of onset in primary progressive MS was 43.9 (median 45) (Tab. 2). The difference in age at onset between the two phenotypes was significant $(p<0.001)$.

\section{Diagnosis:}

The mean delay from onset to diagnosis of all our patients was 5.9 years, though the median was 3 years. One patient who had waited 50 years from onset before contacting a doctor was considered 
an outlier and was removed. However over the last decade, the mean delay from onset to diagnosis before 2005 was 6.4 years (median 3.5) and from 2005 to 2013 it was 5.5 years (median 2.0). The median time from symptom onset to diagnosis of primary progressive disease was 2.5 years.

The most common onset symptom in RR-MS patients was sensory symptoms (29.6\%) followed by optic neuritis (19.1\%). In PP-MS patients the most common symptom was pyramidal symptoms (40.8\%), usually walking difficulties. When dividing all MS patients regardless of disease phenotype into two groups, those diagnosed before $2005(n=284)$ and those diagnosed 2005 or after $(n=295)$, we found that $22.7 \%$ of patients had sensory symptoms as the main symptom in the group diagnosed before 2005. This number rose to 32.0\% in the group diagnosed after $2005(p=0.01)$.

\section{Discussion}

Although Norway is one of the countries with the highest prevalence in the world, no nationwide studies of incidence have been performed. We found a point prevalence of 213.8/100 000, in line with the findings in the nationwide study (4) as well as the most recent local studies throughout Norway $(11,12)$ (Fig.1). A prevalence above 200/100 000 was also seen in the UK (13), Canada (14) and parts of Sweden (15). An increase in prevalence is seen in most studies and may reflect improved diagnostic criteria and availability of health care services, but also increased survival in the MS population and the population as a whole. However an increase in incidence, possibly due to changing environmental factors, may be an integral part of the answer, though our study did not specifically investigate this.

In 2012 a national incidence of 5.9/100 000 was postulated (3). We found a relatively high incidence compared to this. We believe this is due to our method, which is arguably more precise, and date of acquisition, as Midgard's incidence is based on epidemiological studies on incidence from the 80 's and 90's, while our numbers are from 2003 and onwards. Our incidence is based on year of diagnosis and not on onset. The overall incidence rate between 2003 and 2012 was 11.8/100 000, though this ranged from 10.2/100 000 between 2003-2007 to 13.1/100 000 between 2008-2012. This is one of the highest incidence rates reported in Norway, though similar or higher incidences have been reported in Scotland (16), parts of Finland (17) and parts of Canada (18) (19), among others. All patients in Buskerud diagnosed with MS after 2003 were diagnosed in accordance with the McDonald criteria.

The incidence of MS in Buskerud's neighbouring county of Vestfold did not show an increase in the study period spanning up to 2002 (20). Edland et al found periodic fluctuations of MS incidence in Vestfold between 1953 and 1983 (21), while a follow-up study showed a stable incidence of 4.5 in the period 1983 to 2002 (20). A stabile incidence over the last 35 years has also been reported in Western Norway (11). Table 1 shows the most recent prevalences and incidences of Buskerud's neighbouring counties. A study on the prevalence and incidence of multiple sclerosis in the United Kingdom found a consistent downward trend in the incidence of MS between 1990 and 2010 (13). However, Norway's neighbouring country Sweden found an increased incidence at 10.2 (2001-08) in a register based incidence study (22). In Oslo the incidence rose from 3.6 (1972-76) to 8.7 (1992-96) (23) but then fell to 6.6 (2001-05) (24). The fall may however be due to the fairly recent high immigration rate in the Oslo area. MS incidence has also increased over the last $30-40$ years in the north of Norway (12) from 0.7 in 1970-74 to 10.1 in 2005-09 and in central parts of neighbouring 
Finland (25). However, an increase in MS incidence could also be due to improved health care facilities, the availability of more MRI machines and more efficient medications which drive the need to diagnose multiple sclerosis early. Our numbers could suggest an increase in incidence, especially when comparing to neighbouring regions, but the time frame of 10 years is short and the jump from 2003-2007 to 2008-2012 only underlines the importance of long term data when postulating an increase in incidence. The increase in incidence is possibly even more pronounced as the delay from onset to diagnosis in the latest period may cause an underestimation.

The mean age at onset was 33.6 years for RR-MS and 43.9 in progressive (PP) disease, with a mean of 35.4 years for both groups combined. Compared to older studies in neighbouring counties (21), this is slightly higher with Edland reporting an average age of 26 in 1963 and 31.4 in 1983, Celius reporting an average age of 32.1 in 1999 (23) and Lund reporting an average age of 32.5 in 2003 (20). Whether this increase is due to change in diagnostic criteria, environmental factors or simply due to chance is unknown. However it may suggest we are now diagnosing more patients with benign disease that would have remained undiagnosed before the introduction of the McDonald criteria and disease modifying drugs. Other, more recent studies from Norway have found both slightly lower and higher age of onset than ours (11), with an average age of onset in the north of Norway being as high as 40 years (12).

We found a lengthy delay from onset to diagnosis of 5.9 years. The median time from onset to diagnosis was 3 years. This is relatively high, though in accordance with other Norwegian studies (12, $20,23)$. However, when only including patients diagnosed in 2005 or after, the mean delay from onset to diagnosis is slightly reduced to 5.5 years (median 2 ). This difference is not significant $(p=0.19)$. The median time from onset to diagnosis in primary progressive disease was 2.5 years.

We focused on the most debilitating symptom at onset, regardless of other symptoms. Thus a patient with paraplegia and urinary retention due to a medullary lesion would be categorised as having pyramidal symptoms at onset as this was considered the most debilitating symptom. An Oslo study classifying MS symptoms similarly between 1972 and 1999 (23) found that 30\% of patients with MS had pyramidal symptoms at onset and $32 \%$ of patients had sensory symptoms. In our study, $22 \%$ of all patients had pyramidal symptoms at onset, while $27 \%$ had sensory symptoms. Sensory symptoms at onset are associated with more benign disease progression(26). Sensory symptoms were more common in patients with disease onset after 2005. A significant increase in cases with sensory compared to pyramidal symptoms at onset may again support the hypothesis that incidence is rising in part due to diagnosing more benign cases. The majority of patients with relapsing disease described sensory symptoms at onset, while patients with primary progressive disease defined pyramidal symptoms as the first symptom, in line with a more aggressive disease course in PP-MS.

$53.6 \%$ of our patients at the time of prevalence were thought to have a relapsing-remitting disease phenotype and the mean age in this group was 45.9 versus 52.7 years in the Buskerud MS population as a whole. Thus a large portion of our patients are in the middle of child-bearing and working age, emphasising the huge socioeconomic impact this group represents if rendered disabled by relapses or progressive disease $(27,28)$. Disease modifying drugs and other MS-related care is costly. One study by Svendsen et al (29) found that the cost of MS patients to the Norwegian society in 2002 was $€ 439$ million. Direct economic costs accounted for $39 \%$ and this was more than 7 times higher at 
EDSS (Expanded Disability Status Scale(30)) -levels 7-8 compared to levels 1-2. This does not even quantify the personal and social burden the disease has on the patient and their family. This highlights the need to perform updated, good quality prevalence studies to be able to plan future health care.

In conclusion, our findings from Buskerud county are in line with other reports of a high prevalence of multiple sclerosis in Norway, but the incidence is high and may still be increasing. Further studies are needed to investigate the underlying causes of the increasing incidence.

\section{Acknowledgements}

We would like to thank all the patients that were included in this study as well as Dr Einar Kinge at Sandvika Neurological Centre and private neurologist Dr Arne Andersen.

\section{Conflicts of Interest}

CSS has received funding from The Odd Fellow Research Fund for Multiple Sclerosis as well as travel and speakers fees from Biogen Idec. EGC has received funding for travel and speaker's fees from Sanofi-Aventis, Merck Serono, Genzyme, Biogen Idec, Teva, Almirall and Novartis, and received unrestricted research support from Biogen Idec and Novartis. AE has received travel and speaker's fees from Sanofi-Aventis, Merck Serono, Genzyme, Biogen Idec, Teva, Almirall and Novartis, and received research support from Biogen Idec. PBH received an unrestricted research grant from Novartis and funding for travel or speaker's fees from Novartis, UCB, Biogen idec and Teva.

Word count: 2537

\section{References}

1. Dutta R, Trapp BD. Pathogenesis of axonal and neuronal damage in multiple sclerosis. Neurology. 2007;68(22 Suppl 3):S22-31; discussion S43-54.

2. Swank RL, Lerstad O, Strom A, Backer J. Multiple sclerosis in rural Norway its geographic and occupational incidence in relation to nutrition. The New England journal of medicine. 1952;246(19):722-8.

3. Midgard R. Incidence and prevalence of multiple sclerosis in Norway. Acta neurologica Scandinavica Supplementum. 2012(195):36-42.

4. Berg-Hansen P, Moen SM, Harbo HF, Celius EG. High prevalence and no latitude gradient of multiple sclerosis in Norway. Multiple sclerosis. 2014;20(13):1780-2.

5. Buskerud Fylkeskommune: Take A Look at Opportunities in Buskerud [internet] 01.10.2011 [cited 06.08.15] Available from: http://www.bfk.no/Documents/BFK/Om\%20Buskerud/Buskerudbrosjyre\%20engelsk.pdf. 6. Poser CM, Paty DW, Scheinberg L, McDonald WI, Davis FA, Ebers GC, et al. New diagnostic criteria for multiple sclerosis: guidelines for research protocols. Annals of neurology. 1983;13(3):22731.

7. Polman $\mathrm{CH}$, Reingold SC, Banwell B, Clanet M, Cohen JA, Filippi M, et al. Diagnostic criteria for multiple sclerosis: 2010 revisions to the McDonald criteria. Annals of neurology. 2011;69(2):292-302.

8. Polman CH, Reingold SC, Edan G, Filippi M, Hartung HP, Kappos L, et al. Diagnostic criteria for multiple sclerosis: 2005 revisions to the "McDonald Criteria". Annals of neurology. 2005;58(6):840-6.

9. McDonald WI, Compston A, Edan G, Goodkin D, Hartung HP, Lublin FD, et al. Recommended diagnostic criteria for multiple sclerosis: guidelines from the International Panel on the diagnosis of multiple sclerosis. Annals of neurology. 2001;50(1):121-7.

10. Lublin FD, Reingold SC, Cohen JA, Cutter GR, Sorensen PS, Thompson AJ, et al. Defining the clinical course of multiple sclerosis: the 2013 revisions. Neurology. 2014;83(3):278-86. 
11. Grytten N, Aarseth JH, Lunde HM, Myhr KM. A 60-year follow-up of the incidence and prevalence of multiple sclerosis in Hordaland County, Western Norway. Journal of neurology, neurosurgery, and psychiatry. 2015.

12. Benjaminsen E, Olavsen J, Karlberg M, Alstadhaug KB. Multiple sclerosis in the far north incidence and prevalence in Nordland County, Norway, 1970 inverted question mark2010. BMC neurology. 2014;14(1):226.

13. Mackenzie IS, Morant SV, Bloomfield GA, MacDonald TM, O'Riordan J. Incidence and prevalence of multiple sclerosis in the UK 1990-2010: a descriptive study in the General Practice Research Database. Journal of neurology, neurosurgery, and psychiatry. 2014;85(1):76-84.

14. Beck CA, Metz LM, Svenson LW, Patten SB. Regional variation of multiple sclerosis prevalence in Canada. Multiple sclerosis. 2005;11(5):516-9.

15. Svenningsson A, Salzer J, Vagberg M, Sundstrom P, Svenningsson A. Increasing prevalence of multiple sclerosis in Vasterbotten County of Sweden. Acta neurologica Scandinavica. 2015.

16. Rothwell PM, Charlton D. High incidence and prevalence of multiple sclerosis in south east Scotland: evidence of a genetic predisposition. Journal of neurology, neurosurgery, and psychiatry. 1998;64(6):730-5.

17. Sumelahti ML, Tienari PJ, Wikstrom J, Palo J, Hakama M. Regional and temporal variation in the incidence of multiple sclerosis in Finland 1979-1993. Neuroepidemiology. 2000;19(2):67-75.

18. Marrie RA, Yu N, Blanchard J, Leung S, Elliott L. The rising prevalence and changing age distribution of multiple sclerosis in Manitoba. Neurology. 2010;74(6):465-71.

19. Warren SA, Svenson LW, Warren KG. Contribution of incidence to increasing prevalence of multiple sclerosis in Alberta, Canada. Multiple sclerosis. 2008;14(7):872-9.

20. Lund C, Nakken KO, Edland A, Celius EG. Multiple sclerosis and seizures: incidence and prevalence over 40 years. Acta neurologica Scandinavica. 2014;130(6):368-73.

21. Edland A, Nyland H, Riise T, Larsen JP. Epidemiology of multiple sclerosis in the county of Vestfold, eastern Norway: incidence and prevalence calculations. Acta neurologica Scandinavica. 1996;93(2-3):104-9.

22. Ahlgren C, Oden A, Lycke J. High nationwide prevalence of multiple sclerosis in Sweden. Multiple sclerosis. 2011;17(8):901-8.

23. Celius EG, Vandvik B. Multiple sclerosis in Oslo, Norway: prevalence on 1 January 1995 and incidence over a 25-year period. European journal of neurology : the official journal of the European Federation of Neurological Societies. 2001;8(5):463-9.

24. Smestad C, Sandvik L, Holmoy T, Harbo HF, Celius EG. Marked differences in prevalence of multiple sclerosis between ethnic groups in Oslo, Norway. Journal of neurology. 2008;255(1):49-55.

25. Sarasoja T, Wikstrom J, Paltamaa J, Hakama M, Sumelahti ML. Occurrence of multiple sclerosis in central Finland: a regional and temporal comparison during 30 years. Acta neurologica Scandinavica. 2004;110(5):331-6.

26. Weinshenker BG, Bass B, Rice GP, Noseworthy J, Carriere W, Baskerville J, et al. The natural history of multiple sclerosis: a geographically based study. 2. Predictive value of the early clinical course. Brain : a journal of neurology. 1989;112 ( Pt 6):1419-28.

27. Reese JP, John A, Wienemann G, Wellek A, Sommer N, Tackenberg B, et al. Economic burden in a German cohort of patients with multiple sclerosis. European neurology. 2011;66(6):311-21.

28. Parise H, Laliberte F, Lefebvre P, Duh MS, Kim E, Agashivala N, et al. Direct and indirect cost burden associated with multiple sclerosis relapses: excess costs of persons with MS and their spouse caregivers. Journal of the neurological sciences. 2013;330(1-2):71-7.

29. Svendsen B, Myhr KM, Nyland H, Aarseth JH. The cost of multiple sclerosis in Norway. The European journal of health economics : HEPAC : health economics in prevention and care. 2012;13(1):81-91.

30. Kurtzke JF. Rating neurologic impairment in multiple sclerosis: an expanded disability status scale (EDSS). Neurology. 1983;33(11):1444-52. 
31. Risberg G, Aarseth JH, Nyland H, Lauer K, Myhr KM, Midgard R. Prevalence and incidence of multiple sclerosis in Oppland County: a cross-sectional population-based study in a landlocked county of Eastern Norway. Acta neurologica Scandinavica. 2011;124(4):250-7.

32. Kartverket. Creative Commons Attribution ShareAlike 3.0. 2015. 
Tables and Figures

\begin{tabular}{|l|c|c|c|c|}
\hline County & $\begin{array}{c}\text { Year of } \\
\text { prevalence }\end{array}$ & $\begin{array}{c}\text { Prevalence } \\
(\mathbf{1 0 0} \text { 000) }\end{array}$ & $\begin{array}{c}\text { Incidence } \\
\text { period }\end{array}$ & $\begin{array}{c}\text { Incidence } \\
\text { (/100 000) }\end{array}$ \\
\hline $\begin{array}{l}\text { Oppland } \\
\text { (Risberg et } \\
\text { al 2011)(31) }\end{array}$ & 2002 & 174.4 & $1994-1998$ & 7.4 \\
\hline $\begin{array}{l}\text { Hordaland } \\
\text { (Grytten et } \\
\text { al, 2015) } \\
(11)\end{array}$ & 2013 & 211.4 & $2003-2007$ & 8.5 \\
\hline $\begin{array}{l}\text { Vestfold } \\
\text { (Lund } \\
\text { 2014)(20) }\end{array}$ & 2003 & 166.8 & $1983-2002$ & 4.5 \\
\hline $\begin{array}{l}\text { Oslo } \\
\text { (Smestad, } \\
\text { 2008)(24) }\end{array}$ & 2006 & $170 *$ & $2001-2005$ & 6.6 \\
\hline
\end{tabular}

Table 1: studies of prevalence and incidence in neighbouring counties * ethnic Norwegians 


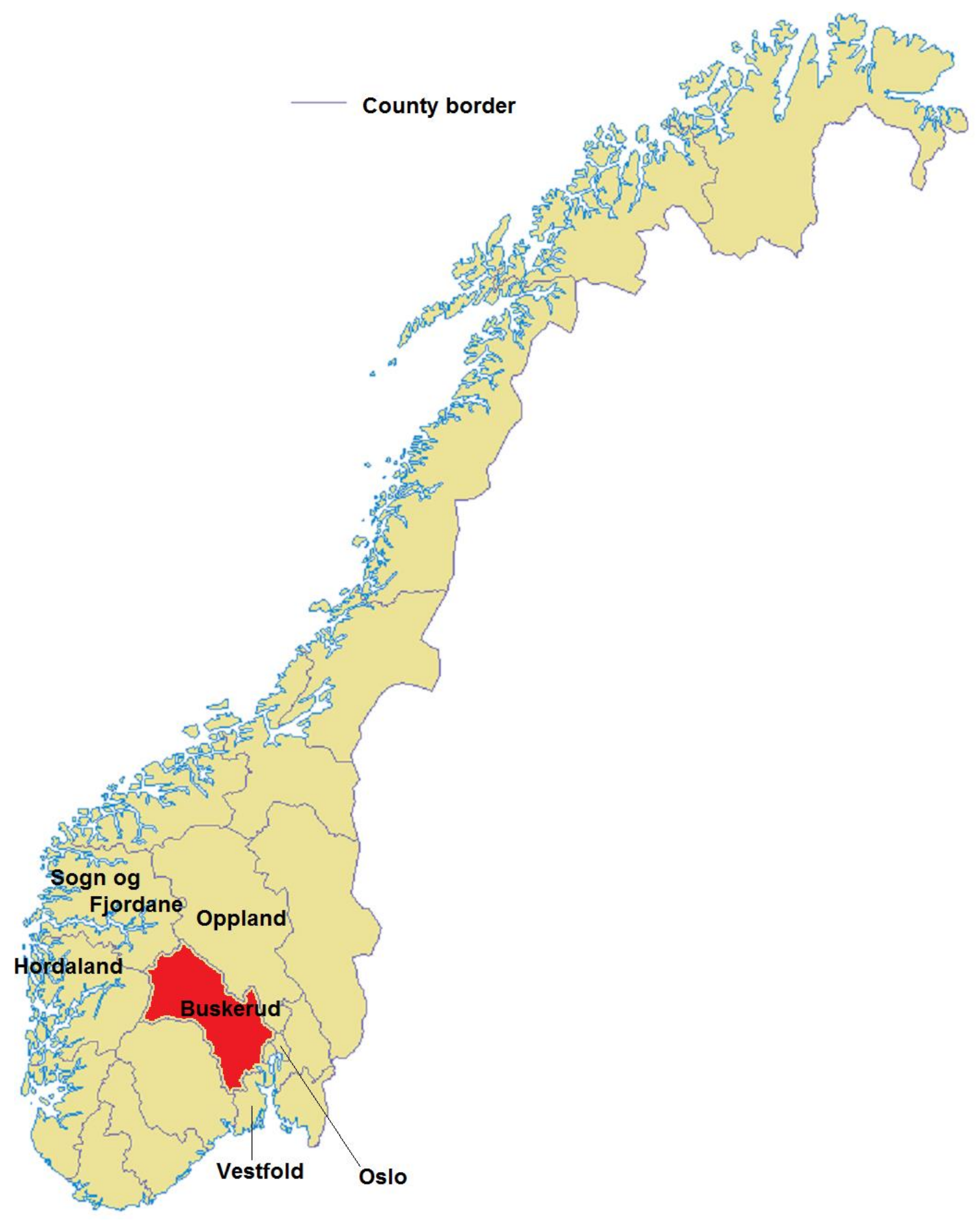

Figure 1: Map of Norway with Buskerud in red, adapted from original map courtesy of Kartverket (32) 


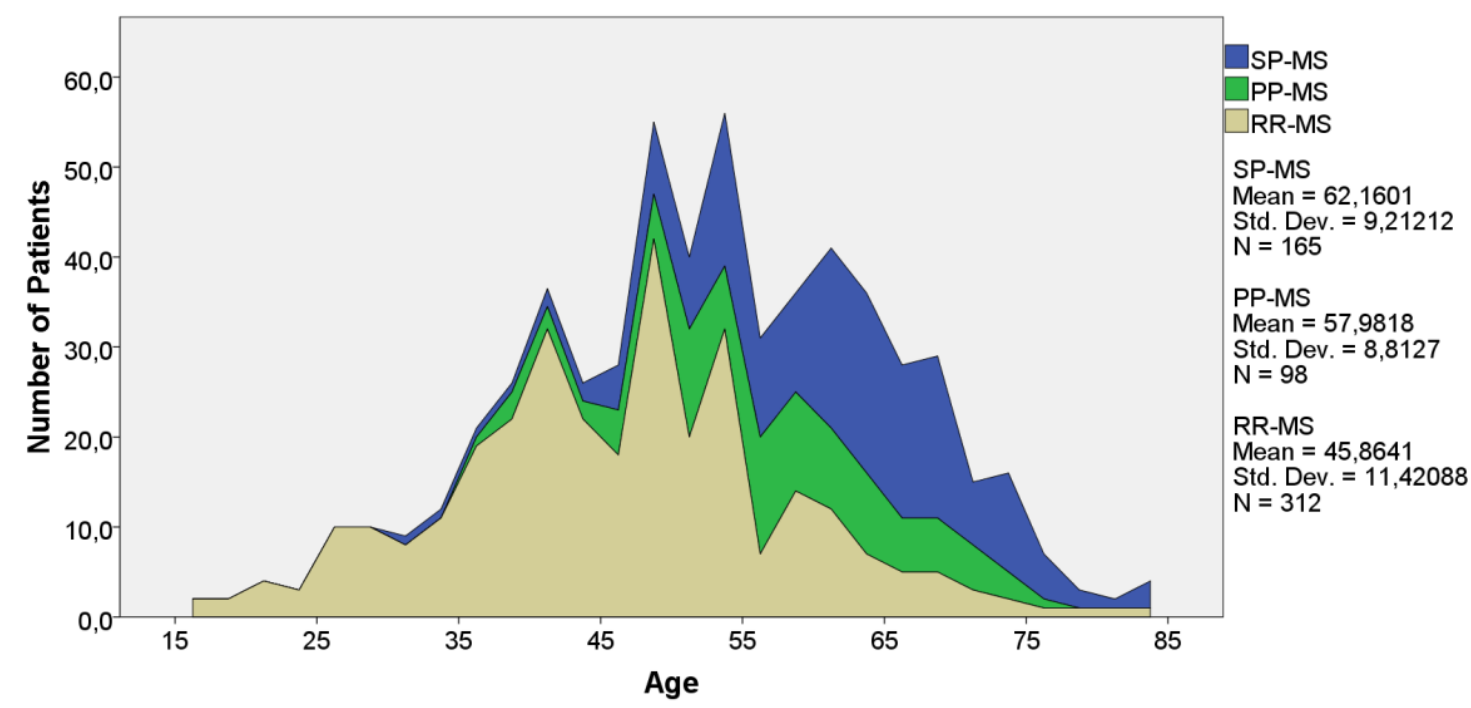

Figure 2: The age-distribution of the MS population by disease phenotype. Number $(N)$ and mean age with standard deviations are given for the patients in each MS phenotype.

\begin{tabular}{|c|c|c|c|c|c|c|c|c|}
\hline & Total (\%) & $\begin{array}{c}\text { Crude } \\
\text { incidence* } \\
/ 100000 \\
(96 \% \mathrm{Cl})\end{array}$ & $\begin{array}{c}\text { Age } \\
\text { adjusted* }^{+} \\
\text {Incidence } \\
/ 100000 \\
(95 \% \mathrm{Cl})\end{array}$ & $\begin{array}{c}\text { Crude } \\
\text { prevalence } \\
/ 100000 \\
(95 \% \mathrm{Cl}) \\
\end{array}$ & $\begin{array}{c}\text { Age adjusted }^{+} \\
\text {prevalence } \\
/ 100000 \\
(95 \% \mathrm{Cl})\end{array}$ & $\begin{array}{c}\text { Mean age } \\
\text { of onset } \\
(95 \% \mathrm{Cl}) \\
\end{array}$ & $\begin{array}{l}\text { Mean time } \\
\text { from onset to } \\
\text { diagnosis } \\
(95 \% \mathrm{Cl})\end{array}$ & $\begin{array}{c}\text { Median time } \\
\text { from onset to } \\
\text { diagnosis }\end{array}$ \\
\hline All patients & $\begin{array}{c}582 \\
(100)\end{array}$ & $\begin{array}{c}11.8 \\
(10, .6-13.1)\end{array}$ & $\begin{array}{c}11.5 \\
(10.2-12.7)\end{array}$ & $\begin{array}{c}213.8 \\
(196.4-231.1)\end{array}$ & $\begin{array}{c}197.1 \\
(180.1-213.3)\end{array}$ & $\begin{array}{c}35.4 \\
(34.5-36.3)\end{array}$ & $\begin{array}{c}6.0 \\
(5.3-6.6)\end{array}$ & 3 \\
\hline Relapsing onset & $\begin{array}{l}477 \\
(82)\end{array}$ & $\begin{array}{c}9.4 \\
(8.3-10.6)\end{array}$ & & $\begin{array}{c}175,2 \\
(159.5-190.9)\end{array}$ & & $\begin{array}{c}33.6 \\
(32,7-34,6)\end{array}$ & $\begin{array}{c}6.3 \\
(5.5-7.0)\end{array}$ & 3 \\
\hline Progressive onset & $\begin{array}{c}98 \\
(16.8)\end{array}$ & $\begin{array}{c}2.4 \\
(1.8-2.9)\end{array}$ & & $\begin{array}{c}36 \\
(28.9-43.1) \\
\end{array}$ & & $\begin{array}{c}43,9 \\
(41.7-46.1)\end{array}$ & $\begin{array}{c}4.5 \\
(3.4-5.6)\end{array}$ & 2.5 \\
\hline Men & $\begin{array}{c}184 \\
(31.6)\end{array}$ & $\begin{array}{c}7.9 \\
(6.4-13.1)\end{array}$ & $\begin{array}{c}7.5 \\
(6.1-8.9)\end{array}$ & $\begin{array}{c}134.7 \\
(115.3-154.2)\end{array}$ & $\begin{array}{c}123.3 \\
(105.3-140.3)\end{array}$ & $\begin{array}{c}36.3 \\
(34.8-37.9)\end{array}$ & $\begin{array}{c}5.0 \\
(4.1-6.0)\end{array}$ & 3 \\
\hline Women & $\begin{array}{r}398 \\
(68.4) \\
\end{array}$ & $\begin{array}{c}15.9 \\
(13.8-18.0)\end{array}$ & $\begin{array}{c}15.4 \\
(13.3-17.4)\end{array}$ & $\begin{array}{c}293.4 \\
(264.7-322.2) \\
\end{array}$ & $\begin{array}{c}272.4 \\
(245.2-299.5)\end{array}$ & $\begin{array}{c}34.9 \\
(33.8-36.1) \\
\end{array}$ & $\begin{array}{c}6.4 \\
(5.6-7.2) \\
\end{array}$ & 3 \\
\hline $\begin{array}{l}\text { Men with RR- } \\
\text { MS/SPMS }\end{array}$ & $\begin{array}{c}144 \\
(24.7)\end{array}$ & & & & & $\begin{array}{c}34.3 \\
(32.7-35.8) \\
\end{array}$ & $\begin{array}{c}5.3 \\
(4.1-6.4)\end{array}$ & 3 \\
\hline $\begin{array}{l}\text { Women with RR- } \\
\text { MS/SPMS }\end{array}$ & $\begin{array}{c}333 \\
(57.2)\end{array}$ & & & & & $\begin{array}{c}33.4 \\
(32.2-34.6)\end{array}$ & $\begin{array}{c}6.7 \\
(5.8-7.7)\end{array}$ & 3 \\
\hline Men with PP-MS & $\begin{array}{c}37 \\
(6.4) \\
\end{array}$ & & & & & $\begin{array}{c}44.5 \\
(40.8-48.2) \\
\end{array}$ & $\begin{array}{c}4.1 \\
(2.5-5.7) \\
\end{array}$ & 3 \\
\hline Women with PP-MS & $\begin{array}{c}61 \\
(10.5)\end{array}$ & & & & & $\begin{array}{c}43.6 \\
(40.8-46.3)\end{array}$ & $\begin{array}{c}4.7 \\
(3.2-6.2)\end{array}$ & 2 \\
\hline
\end{tabular}

Table 2: MS population demographics. Prevalence date is 1st January 2014.

* Incidence between 2003 and 2013

${ }^{+}$Adjusted to the European standard population

In 7 patients initial disease course could not be defined retrospectively. 


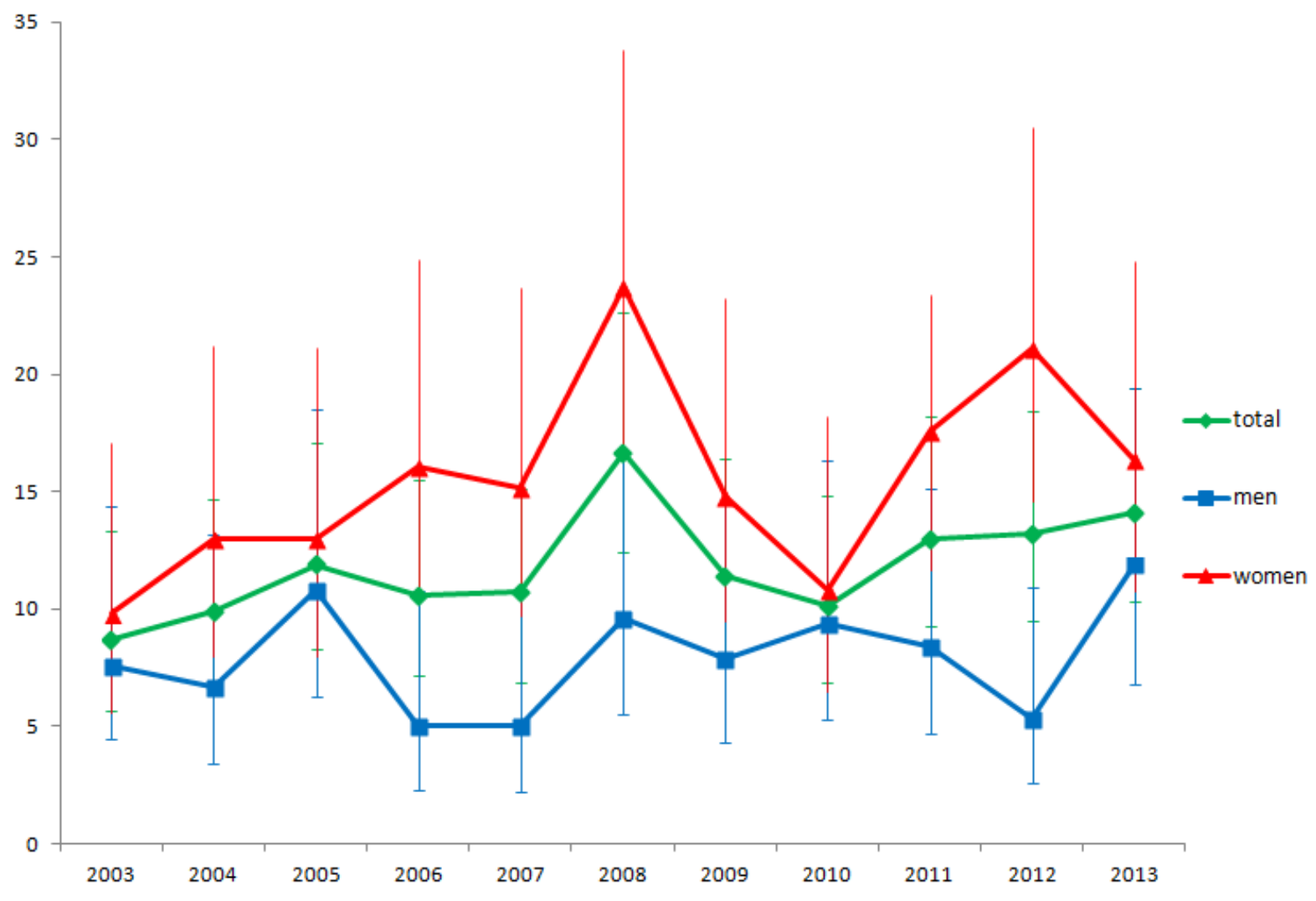

Figure 3: Incidence of MS by years for men, women and total with $95 \% \mathrm{Cl}$.

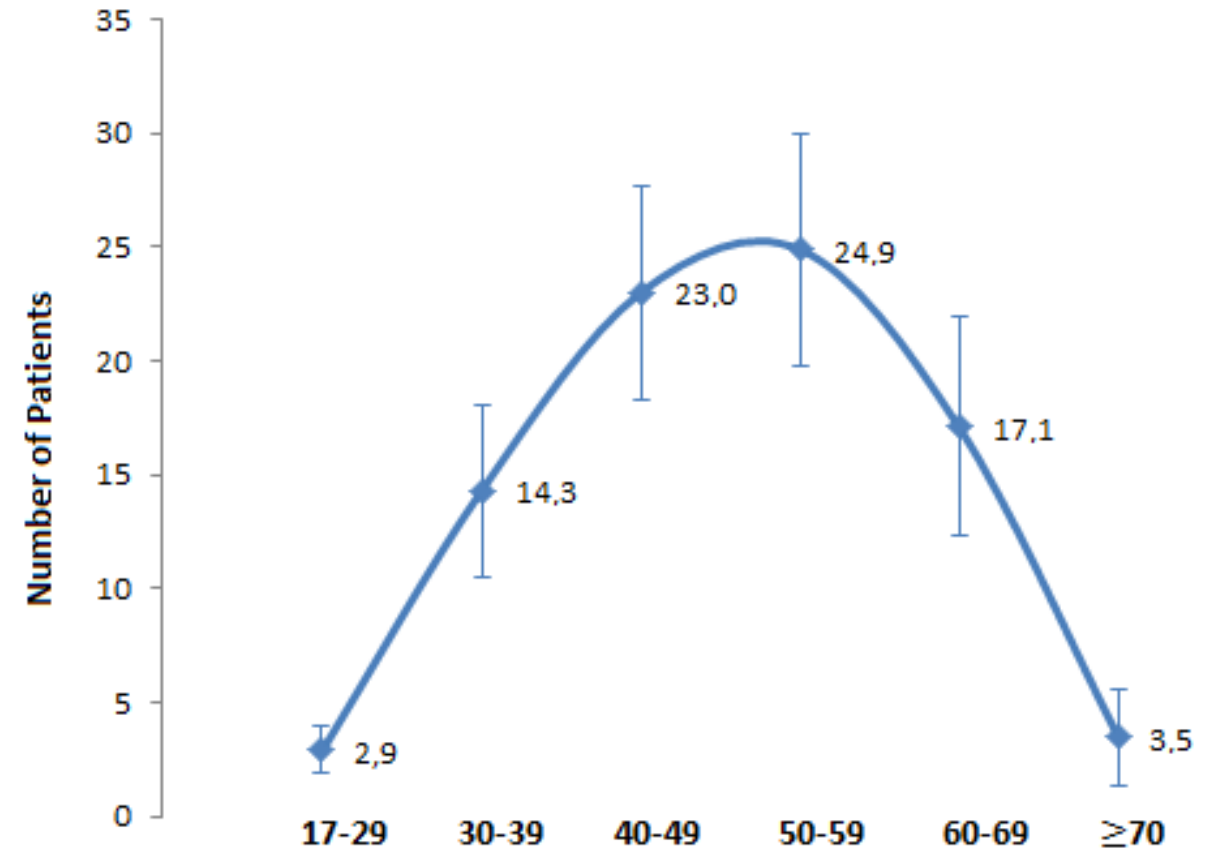

Figure 4: Sex-standardised incidence rates with 95\% confidence interval based on year of diagnosis stratified by age group per 100000. 